\title{
FORCED VIBRATION OF THE ALUMINUM BEAM USING A PIEZOELECTRIC ACTUATOR - EXPERIMENT AND FINITE ELEMENT ANALYSIS
}

\author{
VLADIMÍR GOGA ${ }^{*}$, ŠIMON BERTA* , VLADIMÍR KUTIŠ ${ }^{*}$, GABRIEL GÁLIK* \\ JUSTÍN MURÍN* AND JURAJ PAULECH* \\ * Department of Applied Mechanics and Mechatronics \\ Institute of Automotive Mechatronics \\ Faculty of Electrical Engineering and Information Technology \\ Slovak University of Technology \\ Ilkovičova 3, 81219 Bratislava, Slovak Republic \\ e-mail: vladimir.goga@stuba.sk,www.uamt.fei.stuba.sk
}

Key words: Piezoelectric Actuator, Piezo Material PZT-5H, Beam Vibration, Finite Element Model.

\begin{abstract}
This paper deals with the forced vibration of the aluminum beam using a piezoelectric actuator. Cantilever beam was excited by thin piezoelectric film placed near the fix support. The oscillation of the free end of the beam was measured using a laser displacement sensor. The beam's eigenfrequency and damping ratio for the first bending vibration mode was determined experimentally. The beam's deflection when the beam was excited by a piezoelectric actuator was also determined experimentally. The actuator was controlled by a signal generator and high-performance power supply and linear amplifier module for driving piezoelectric actuators. Data from experimental measurements were used to validate the finite element model of the beam with piezoelectric actuator. Results from experimental measurements and numerical simulations were compared.
\end{abstract}

\section{INTRODUCTION}

The phenomenon of piezoelectricity was discovered in 1880 by Pierre and Paul-Jacques Curie. It occurs in several non-centrosymmetric crystals, such as quartz $\left(\mathrm{SiO}_{2}\right)$, in which electric dipoles (and hence surface charges) are generated when the crystals undergo mechanical deformations. The same crystals also exhibit the converse effect, that is, they undergo mechanical deformations when subjected to electric fields. Based on this phenomenon, the piezo materials can serve as both sensors as well as actuators, for being capable of converting one form of energy into another reversibly, whereby they are classified as transducers [1].

Commercial piezoelectric materials are now available as ceramics and polymers, which can be manufactured into a variety of convenient shapes and sizes. Lead $(\mathrm{Pb})$ zirconate titanate (PZT), a stiff and brittle variant, is the most widely used piezoceramic today. 
Piezopolymers, on the other hand, are very flexible in nature. The most common commercial piezopolymer is the polyvinvylidene fluoride (PVDF). Traditionally, the piezoelectric materials find their use in accelerometers, strain sensors, emitters and receptors of stress waves, vibration sensors, actuators, and pressure transducers. During the last two decades or so, they have been increasingly deployed in turbo-machinery actuators, vibration dampers and for active vibration control of stationary/moving structures. Other areas of use for piezo materials include structural health monitoring (SHM), biomechanics and biomedical engineering and energy harvesting [1].

Piezoelectricity is described mathematically within a material's constitutive equation, which defines how the piezoelectric material's stress $(\boldsymbol{\sigma})$, strain $(\mathbf{S})$, charge-density displacement (D), and electric field (E) interact [2, 3].

The piezoelectric constitutive law in strain-charge form is $[2,3]$ :

$$
\begin{aligned}
& \mathbf{S}=\mathbf{S}_{\mathbf{E}} \boldsymbol{\sigma}+\mathbf{d}^{T} \mathbf{E} \\
& \mathrm{D}=\mathrm{d} \sigma+\varepsilon_{\sigma} \mathbb{E}
\end{aligned}
$$

The matrix $\mathbf{d}$ contains the piezoelectric coupling coefficients (superscript ${ }^{T}$ denotes matrix transposition), matrix $\mathbf{S}_{\mathrm{E}}$ contains compliance coefficients (measured under at least a constant, and preferably a zero, electric field) and matrix $\varepsilon_{\sigma}$ contains coefficients of electric permittivity (measured under at least a constant, and preferably a zero, stress field) [2, 3].

This paper deals with the creation and validation of the finite element model of cantilever beam with a glued thin piezoelectric film actuator. The actuator serves as a source of forced vibration of the bearn. Finite element model is compared with the experimental physical model.

\section{$S^{2}$}
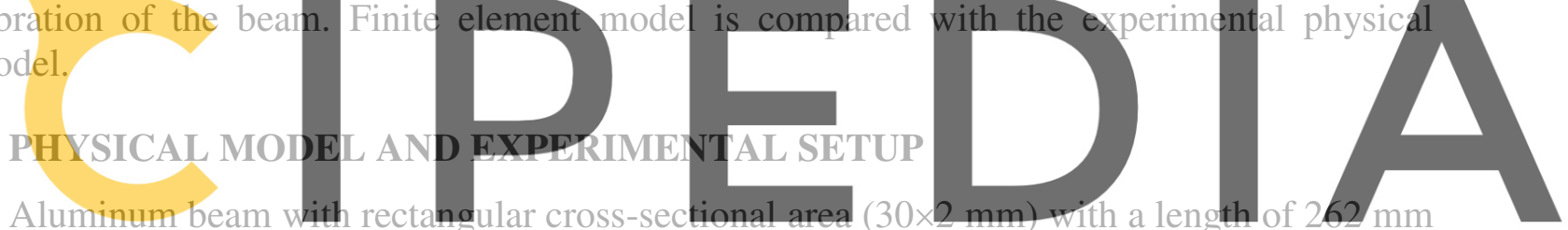

was fixed on one end. Thin piezoelectric film actuator was glued to the beam on one side,

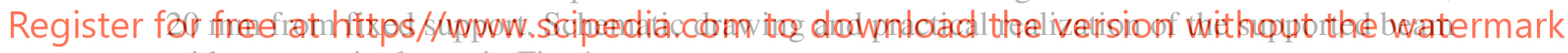
with actuator is shown in Fig. 1.

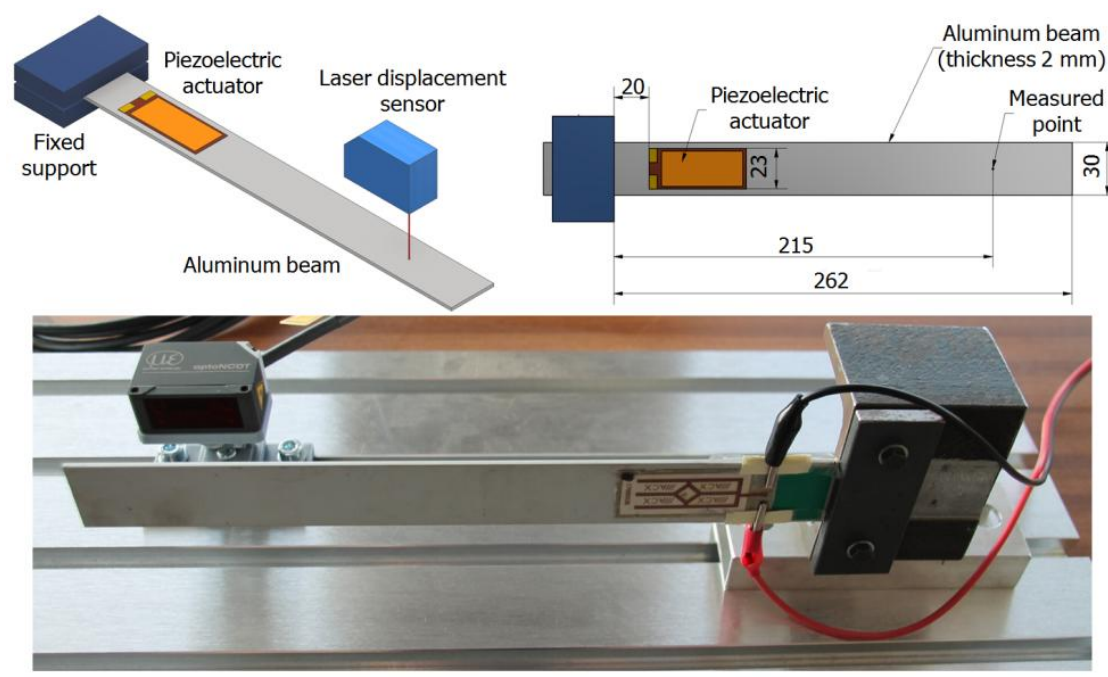

Figure 1: Schematic drawing and practical realization of the supported beam with piezoelectric actuator 
Forced vibration of the beam was realized with a piezoelectric actuator powered by a signal generator via a piezo driver with voltage gain of 20. Beam's displacement was measured at a distance of $215 \mathrm{~mm}$ from the support using a laser displacement sensor. Measured signal from the sensor was fed to the PC using DAQ device and subsequently processed in software LabVIEW.

The experimental setup scheme is shown in Fig. 2 and the parameters of the individual devices are given in Table 1. The real experimental setup is shown in Fig. 3.

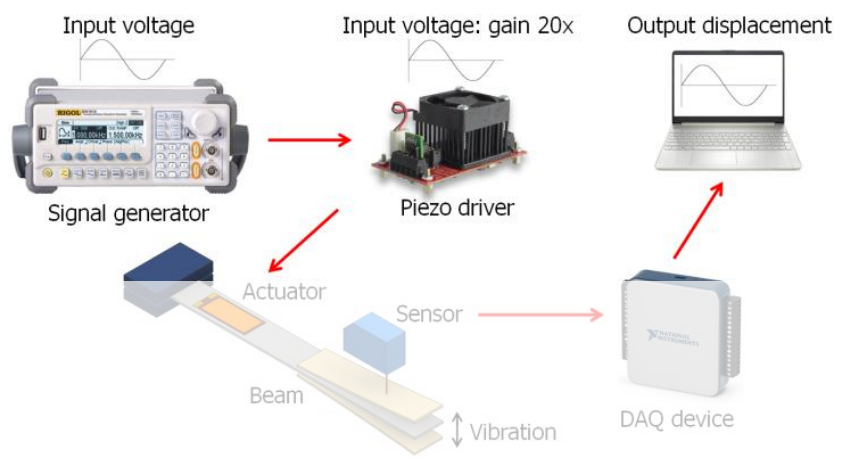

Figure 2: The experimental setup scheme

Table 1: The parameters of the individual devices using in experimental setup
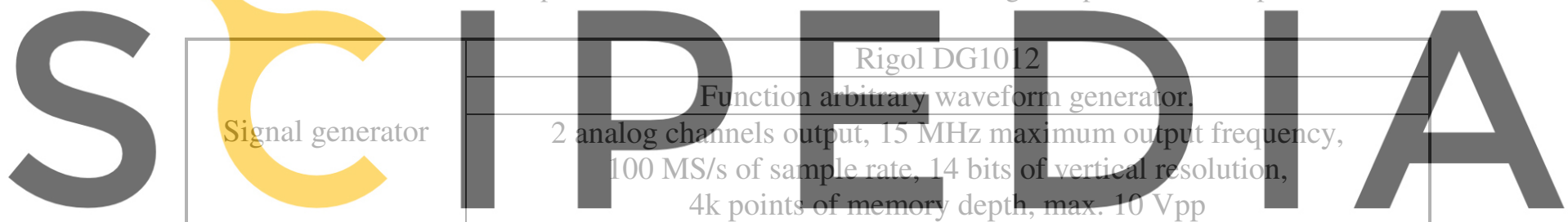

$\mathrm{PDm} 200 \mathrm{~B}$

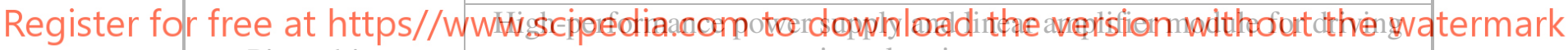

Piezo driver piezoelectric actuators

power supply voltage $+24 \mathrm{~V}$, gain $20 \mathrm{~V} / \mathrm{V}$,

set to work in bipolar voltage output $\pm 100 \mathrm{~V}$ PPA-1001

Single layer product recommended for energy harvesting and sensing

Piezoelectric applications.

actuator

It also exhibits good performance as a resonant actuator.

capacitance $100 \mathrm{nF}$, mass $2.8 \mathrm{~g}$, full scale voltage range $\pm 120 \mathrm{~V}$, piezoelectric material PZT-5H optoNCDT ILD 1320-25

Laser displacement sensor

Uses the principle of optical triangulation, that is, a visible, modulated point of light is projected onto the target surface.

power supply voltage $+24 \mathrm{~V}$, analog output $4-20 \mathrm{~mA}$, measuring range $25 \mathrm{~mm}$, measuring rate $1 \mathrm{kHz}$

DAQ device NI USB-6001

Simple data logging, portable measurements. $8 \mathrm{AI}(14-\mathrm{Bit}, 20 \mathrm{kS} / \mathrm{s}, \pm 10 \mathrm{~V}), 2 \mathrm{AO}(5 \mathrm{kS} / \mathrm{s} / \mathrm{ch}), 13 \mathrm{DIO}, 32$-bit counter 


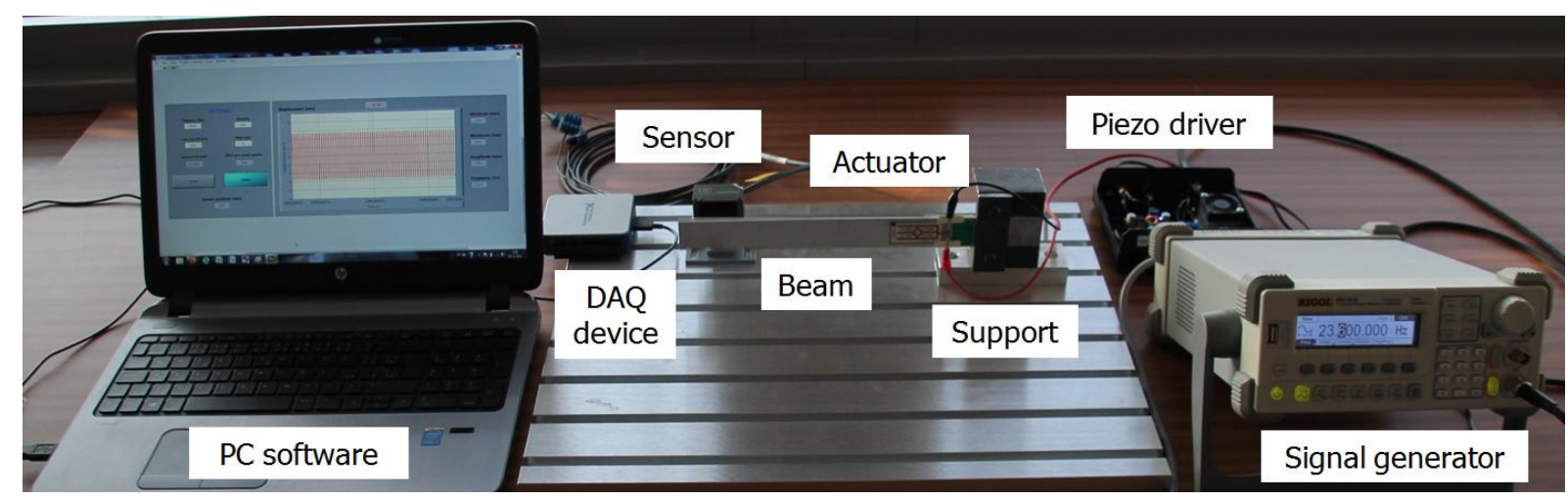

Figure 3: The real experimental setup

\section{EXPERIMENTAL MEASUREMENTS}

Two types of experimental measurements were performed for the purpose of creating and validating the finite element model.

In the first case, the beam was manually deflected and its deflection during free vibration was measured - free vibration test.

In the second case, the beam's vibrations were caused by the action of the piezoelectric actuator and beam's deflection was measured - forced vibration test.

\subsection{Free vilbration test}

The beam's free end
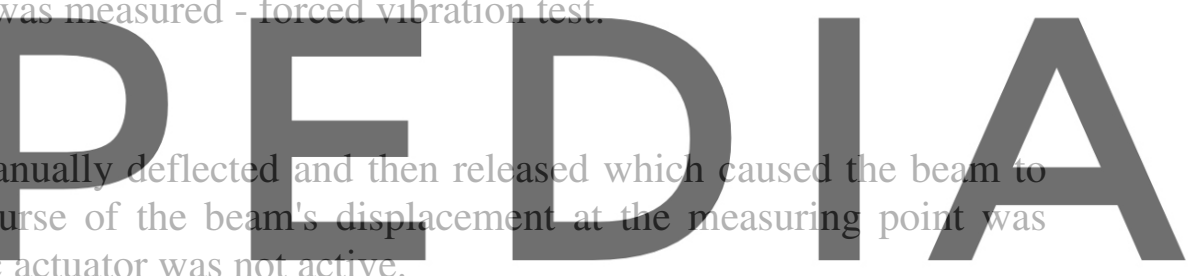

measured (Fig. 4). Piezoelectric actuator was not active.

The eigenfrequency $f_{0}=23.6 \mathrm{~Hz}$ and damping ratio $\zeta=0.6 \%$ of the beam's $1^{\text {st }}$ bending

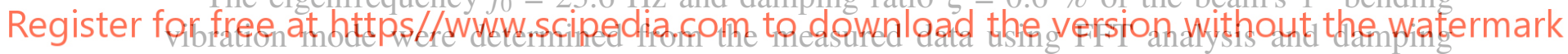
envelope.

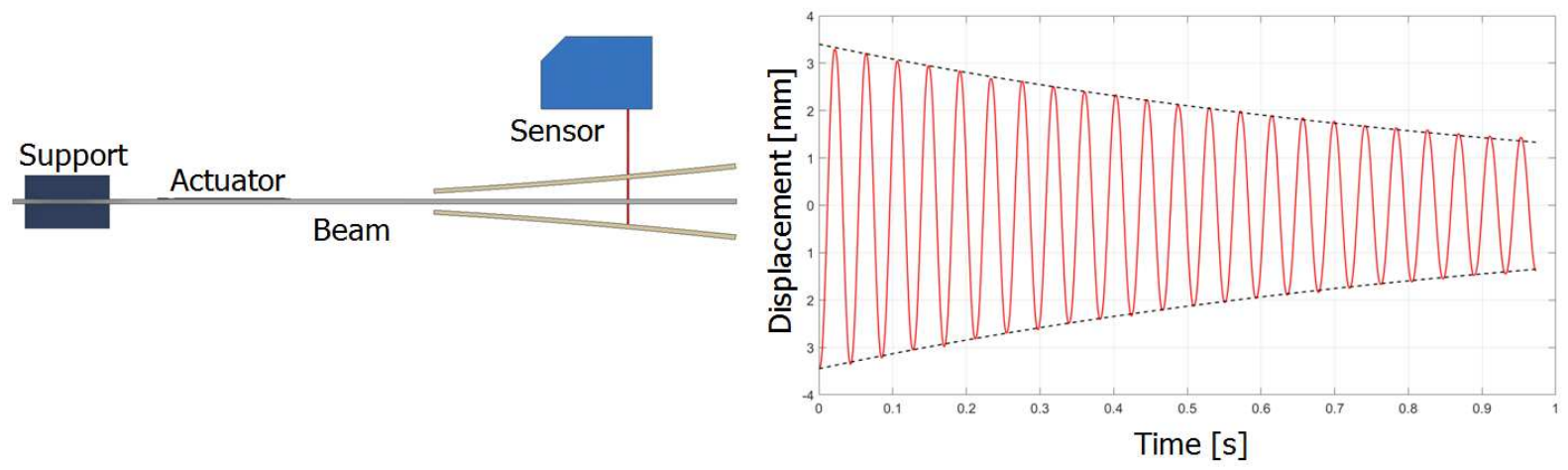

Figure 4: Free vibration test: $1^{\text {st }}$ bending vibration mode (black dashed line - damping envelope: damping ratio $\zeta=0.6 \%$ ) 


\subsection{Forced vibration test}

Forced vibration of the beam was realized with a piezoelectric actuator powered by a signal generator via a piezo driver with voltage gain of 20. Sinusoidal input voltage signal with different amplitude level was generated and fed to the piezoelectric actuator, while the beam's output displacement amplitude was measured. Frequency of the input signal was tuned to the beam's eigenfrequency $f_{0}=23.6 \mathrm{~Hz}$. Table 2 presents beam's displacement amplitudes $A$ for different amplitudes of the input voltage signal $U_{\text {amp. }}$.

Fig. 5 shows the beam's measured displacement amplitude-frequency characteristics in the vicinity of eigenfrequency for two input voltage signals with amplitude $U_{\text {amp }}=1$ and $1.5 \mathrm{~V}$.

Table 2: Beam's displacement amplitudes $A$ for different amplitudes of the input voltage signal $U_{\text {amp}}$, measured data

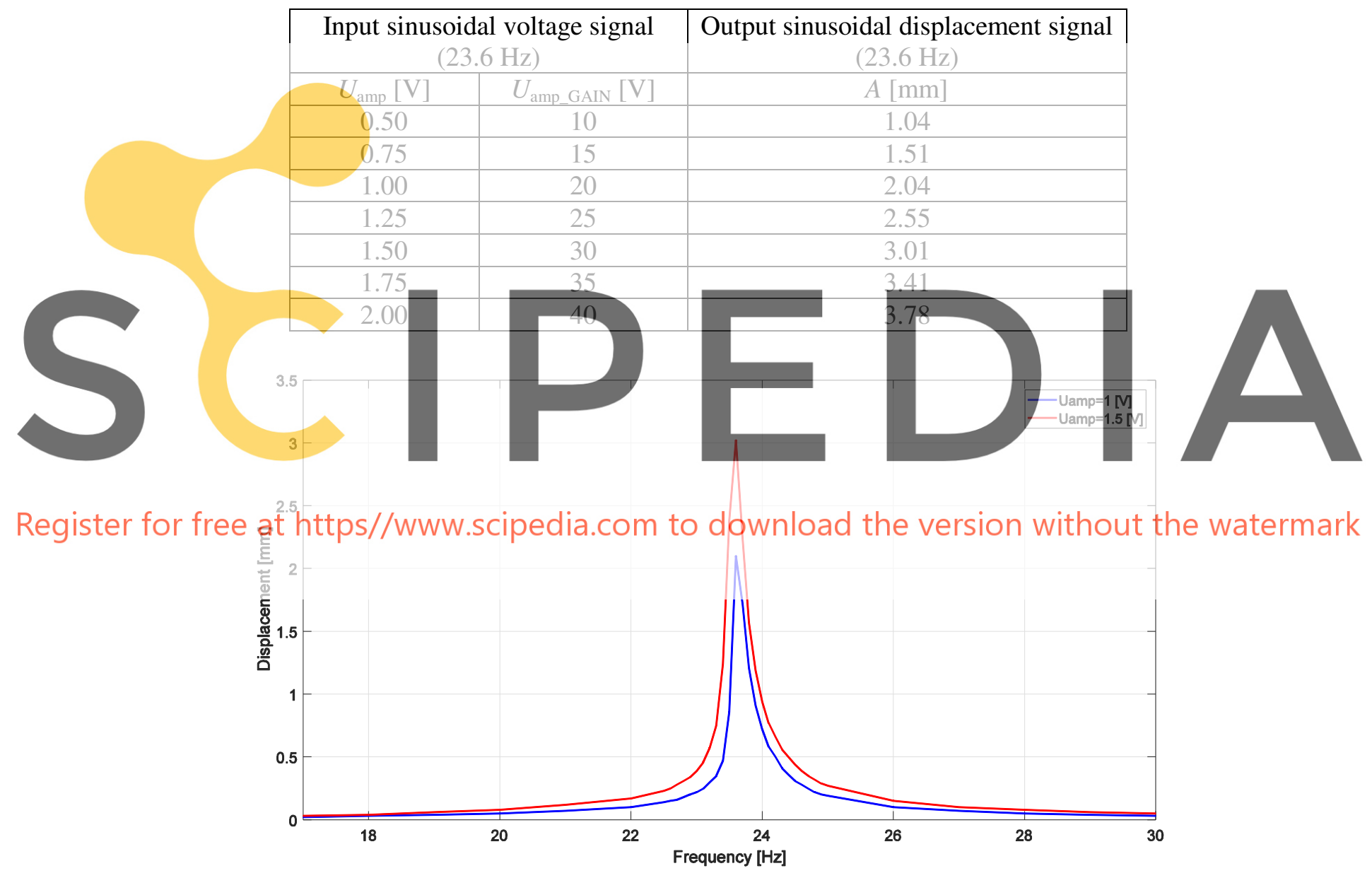

Figure 5: Forced vibration test: displacement amplitude-frequency characteristics 


\section{FINITE ELEMENT MODEL}

Geometries of the cantilever beam, support and piezoelectric actuator were created in Design Modeler of Ansys Workbench according to the dimensions of the real model structures (except for support, which has no effect on the results of finite element analyses).

Piezoelectric actuator was modelled as one thin layer $(0.15 \mathrm{~mm})$ of the material with piezoelectric properties according to its datasheet [4]. Other support layers of the actuator were neglected to simplify the model.

Mesh of the finite element model is shown in Fig. 6. Hexahedral elements with uniform size (but with different size for individual solids) were used for the mesh since the model consists of only simple orthogonal solids. For the beam and the piezoelectric actuator 3 layers of elements were used (as shown in detail view in Fig. 6) to better represent their behaviour in simulated deflections. For the piezoelectric actuator, element type SOLID226 with coupled physics capabilities was used, which has piezoelectric coupled-field option enabled via custom Ansys APDL command. For other solids, element type SOLID186 was used.
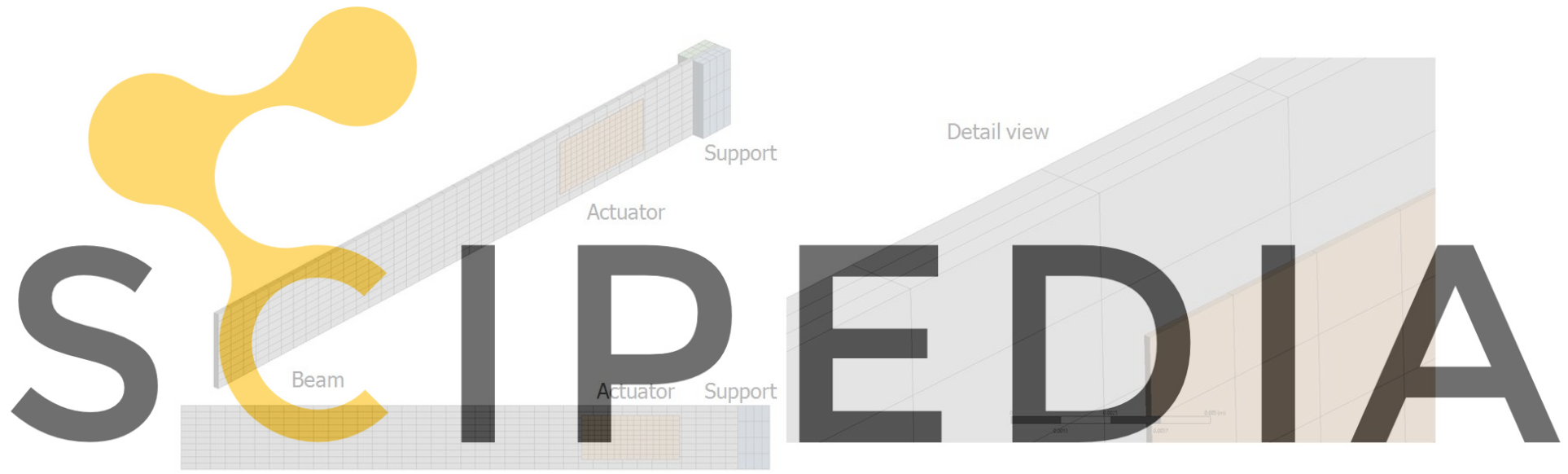

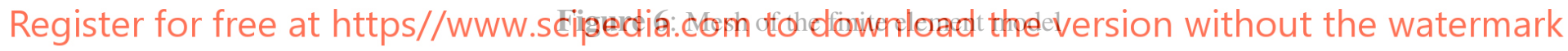

\section{MATERIAL PROPERTIES}

In engineering data of Ansys Workbench material properties were created and subsequently assigned to solids of the finite element model. Structural steel was assigned to support structure and aluminum alloy was assigned to the beam. Material of the piezoelectric actuator is PZT-5H (according to manufacturer's datasheet [4]). Basic mechanical properties for all materials are present in Table 3. Material dependent damping ratio $\zeta_{\text {alu }}=0.4 \%$ was assigned to aluminum alloy. For PZT-5H dielectric loss factor tan $\delta_{e}=2 \%$ has been defined.

Table 3: Material properties of the support, beam and actuator solids

\begin{tabular}{|c|c|c|c|}
\hline & $\begin{array}{c}\text { Young's modulus } \\
{[\mathrm{GPa}]}\end{array}$ & $\begin{array}{c}\text { Density } \\
{\left[\mathrm{kg} / \mathrm{m}^{3}\right]}\end{array}$ & $\begin{array}{c}\text { Poisson's ratio } \\
{[-]}\end{array}$ \\
\hline Support (steel) & 200 & 7850 & 0.3 \\
\hline Beam (aluminum) & 66 & 2750 & 0.3 \\
\hline Actuator (PZT-5H) & 50 & 7800 & 0.31 \\
\hline
\end{tabular}


Mechanical and piezoelectric properties of the actuator's material were inserted and assigned using custom APDL commands in form of coefficients, which form matrices $\mathbf{d}, \mathbf{s}_{\mathbf{E}}$ and $\boldsymbol{\varepsilon}_{\boldsymbol{\sigma}}$ used in mentioned constitutive equations of piezoelectricity (1). Material properties for piezoelectricity of PZT-5H were taken from engineering database with some constants modified according to data given by piezoelectric actuator's manufacturer [4, 5]:

Compliance matrix:

$$
\mathbf{S}_{\mathbf{E}}=\left|\begin{array}{cccccc}
16.5 & -4.78 & -8.45 & 0 & 0 & 0 \\
-4.78 & 16.5 & -8.45 & 0 & 0 & 0 \\
-8.45 & -8.45 & 20.7 & 0 & 0 & 0 \\
0 & 0 & 0 & 43.5 & 0 & 0 \\
0 & 0 & 0 & 0 & 43.5 & 0 \\
0 & 0 & 0 & 0 & 0 & 42.6
\end{array}\right| \times 10^{-12}\left[\mathrm{~m}^{2} / \mathrm{N}\right]
$$

Piezoelectric coupling:

$$
d=\left|\begin{array}{cccccc}
0 & 0 & 0 & 0 & 741 & 0 \\
0 & 0 & 0 & 741 & 0 & 0 \\
-320 & -320 & 650 & 0 & 0 & 0
\end{array}\right| \times 10^{-12}[\mathrm{C} / \mathrm{N}]
$$

\section{Relative permittivity:}
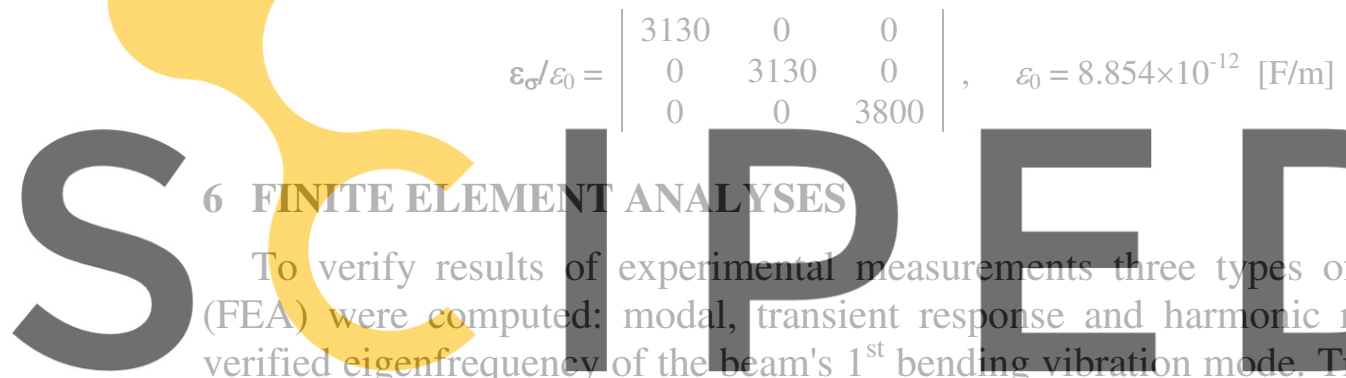

\section{FINITE ELEMEN}

To verify results

(FEA) were computed:

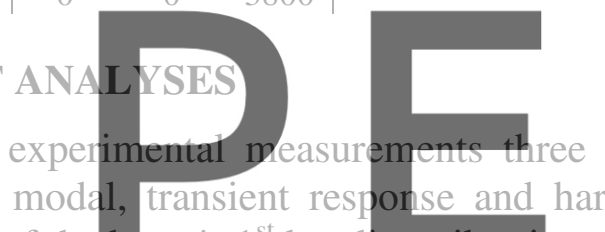

verified eigenfrequency of the he

verified attenuation of beam's free vibration from initial deflection while the actuator was not

\subsection{Modal analysis}

In the modal analysis, the solver range was set to compute eigenfrequencies of the system in range from 0 to $200 \mathrm{~Hz}$. Fixed support (zero displacement) was assigned to one of the support's solid faces. Voltages on nodes of top and bottom faces of the piezoelectric actuator were coupled to form electrodes and then grounded using custom APDL commands. Computed $1^{\text {st }}$ bending vibration eigenfrequency was $23.64 \mathrm{~Hz}$, which is very close to the measured value $23.6 \mathrm{~Hz}$. Shape of the beam's deflection for $1^{\text {st }}$ vibration mode is shown in Fig. 7. 


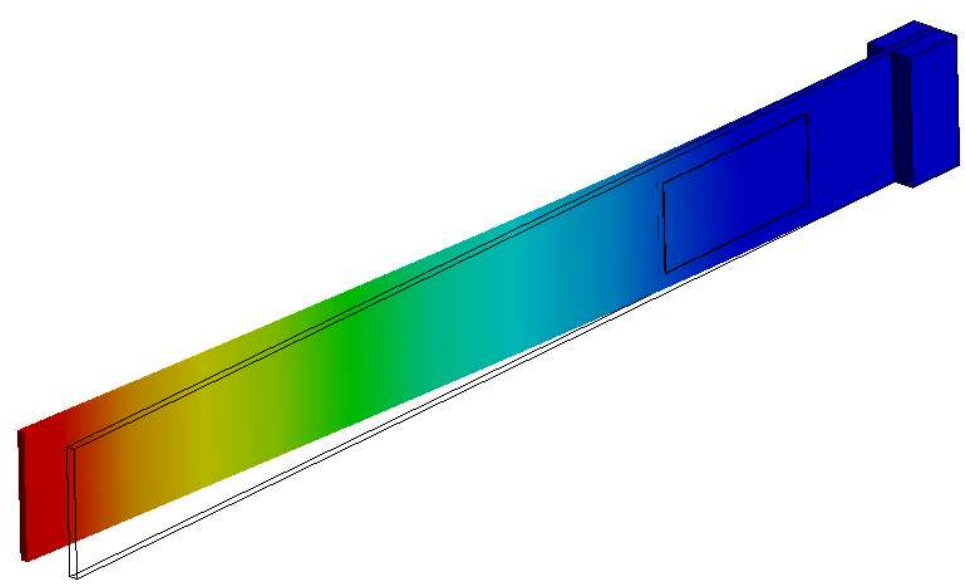

Figure 7: Modal analysis: beam's $1^{\text {st }}$ vibration mode at $23.64 \mathrm{~Hz}$

\subsection{Transient analysis}

In the transient analysis, the solver was set to simulate one second of beam's free vibration from initial deflection. Deflection was measured in sensor distance of $215 \mathrm{~mm}$ from the support. Initial deflection was set to $-3.45 \mathrm{~mm}$, same as in the experimental free vibration test. Fixed support was set the same as in modal analysis. Damping ratio in analysis setting was set to $0.6 \%$. Voltages on nodes of top and bottom faces of the piezoelectric actuator were coupled to form electrodes. Only the bottom electrode was grounded. Comparison betwden results of the free vibiation from experimentally measured and Ansys sinulated data is shown in Fig. 8. Data from measured frec vibration test are a harmonic exponentially decayed signal with calculated frequency $23.6 \mathrm{~Hz}$ and damping ratio $0.6 \%$, whereas simulated dat from Ansys are a harmonic exponentially decayed signal with frequency $23.5 \mathrm{~Hz}$ and damping ratio Register forf free at https//www.scipedia.com to download the version without the watermark

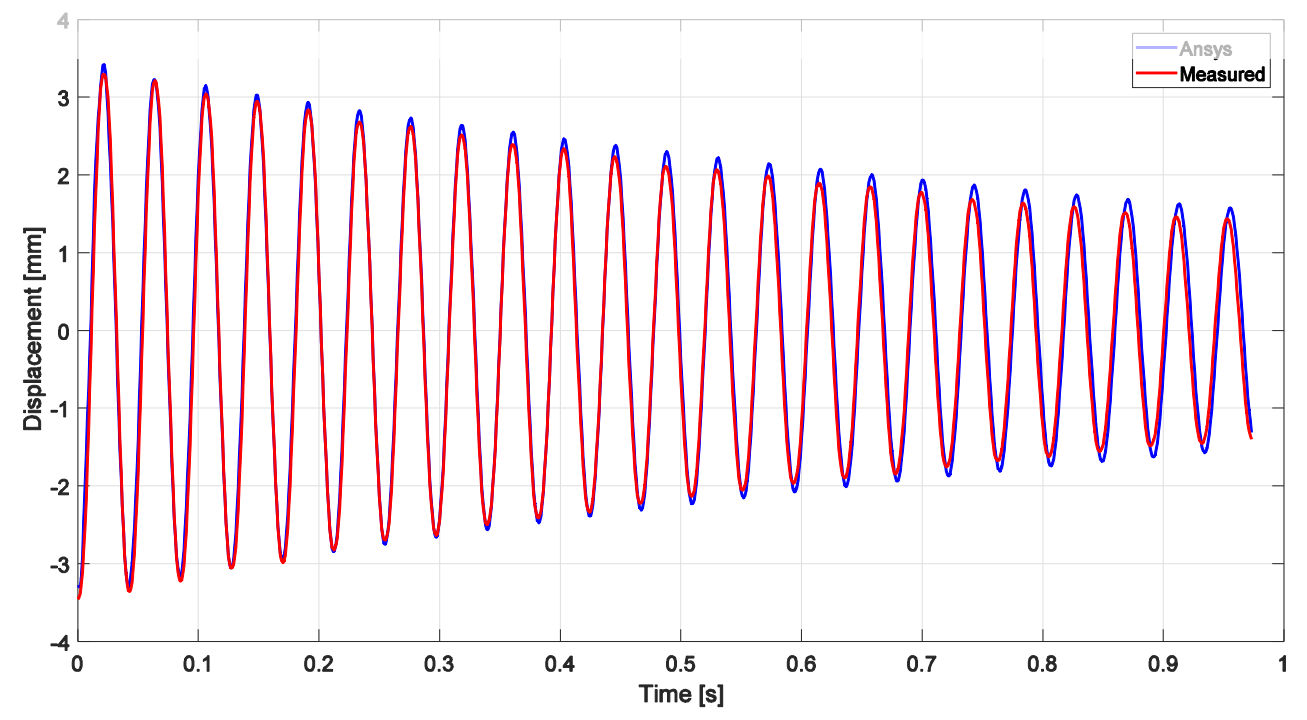

Figure 8: Comparison between free vibration of measured and simulated system 


\subsection{Harmonic analysis}

In the harmonic analysis, the solver range for frequency response was set in range from 17 to $30 \mathrm{~Hz}$ to compute deflection of the beam in sensor distance of $215 \mathrm{~mm}$ from the support. Fixed support was set the same as in the modal and transient analyses. Damping ratio in analysis setting was set to $0.6 \%$. Voltages on nodes of top and bottom faces of the piezoelectric actuator were coupled to form electrodes. Sinusoidal voltage on the top electrode was set to the same amplitudes $\left(U_{\text {amp_GAIN }}\right)$ as in experimental forced vibration test (Table 2 ) using custom APDL commands. The bottom electrode was grounded. Comparison of the measured and simulated beam's displacement amplitudes $A$ for different amplitudes of the input voltage signal $U_{\text {amp }}$ is presented in Table 4.

Table 4: Beam's displacement amplitudes $A$ for different amplitudes of the input voltage signal $U_{\text {amp}}$, measured and simulated data

\begin{tabular}{|c|c|c|c|c|}
\hline \multicolumn{2}{|c|}{$\begin{array}{l}\text { Input sinusoidal voltage signal } \\
\qquad(23.6 \mathrm{~Hz})\end{array}$} & \multicolumn{3}{|c|}{ Output sinusoidal displacement signal $(23.6 \mathrm{~Hz})$} \\
\hline \multirow{2}{*}{$U_{\mathrm{amp}}[\mathrm{V}]$} & \multirow{2}{*}{$U_{\text {amp_GAIN }}[\mathrm{V}]$} & \multicolumn{2}{|c|}{$A[\mathrm{~mm}]$} & \multirow{2}{*}{$\Delta A[\%]$} \\
\hline & & measured & simulated & \\
\hline 0.50 & 10 & 1.04 & 1.05 & 0.96 \\
\hline 0.75 & 15 & 1.51 & 1.54 & 1.99 \\
\hline 1.00 & 20 & 2.04 & 2.01 & -1.47 \\
\hline 1.25 & 25 & 2.55 & 2.51 & -1.57 \\
\hline 1.50 & 30 & 3.01 & 2.98 & -1.00 \\
\hline 1.75 & 35 & 3.4 & 3.48 & 2.05 \\
\hline 2.00 & 40 & 3.78 & 3.94 & 4.23 \\
\hline
\end{tabular}

Ansys simulated beam deflection data in measured point for piezo driver input voltage

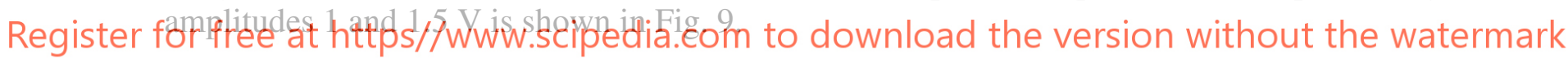
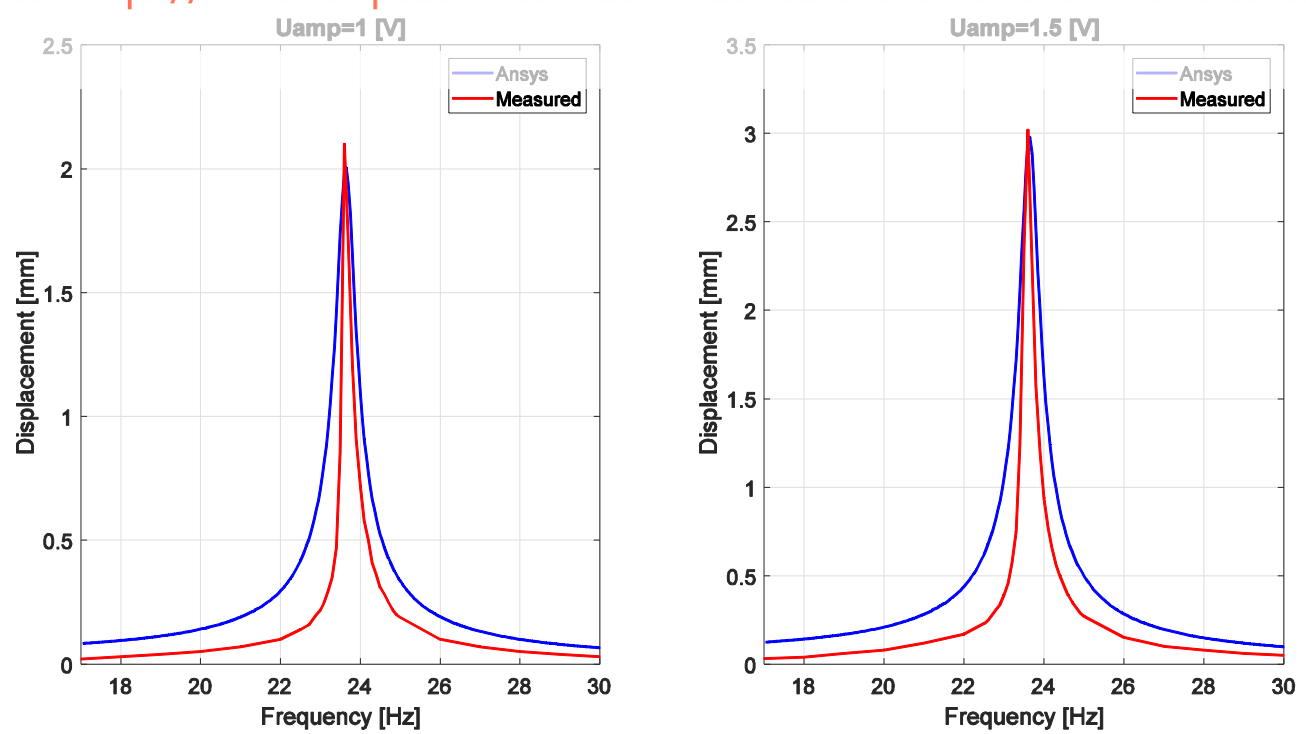

Figure 9: Comparison between frequency response of measured and simulated system 


\section{CONCLUSIONS}

A complex numerical finite element model of the cantilever beam with piezoelectric actuator was created in software Ansys. This model was verified based on the experimental measurements. Results of the real and modeled system were compared using three types of analyses: modal, transient and harmonic. In modal analysis, the eigenfrequency of the beam's $1^{\text {st }}$ bending vibration mode was verified. Damping properties of the system were monitored in free vibration test and transient analysis. Beam's displacement amplitudes vs. driving frequencies of the piezoelectric actuator were evaluated in the harmonic analysis. All analyses show that the finite element model is in very good agreement with the real system. This model will be used in the future for numerical analyses of the actuator as an active damping element and in the study of its energy harvesting capability.

\section{ACKNOWLEDGEMENT}

This work was supported by the Slovak Grant Agency: VEGA 1/0081/18, VEGA 1/0416/21, KEGA 011STU-4/2020 and APVV-19-0406.

\section{REFERENCES}

[1] Bhalla S., Moharana S., Talakokula V., Kaur N.: Piezoelectric Materials: Applications in SHM, Energy Harvesting and Bio-mechanics. Wiley Athena Academic. ISBN : 978-11-

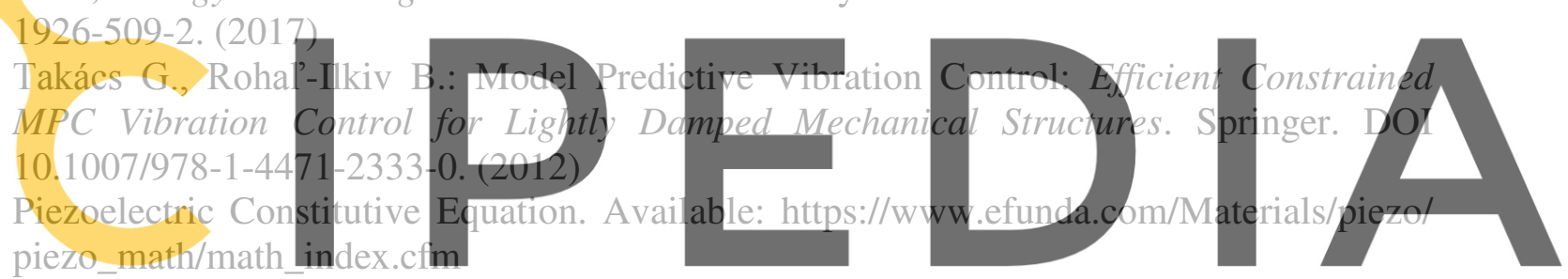

[4] PPA-1001 piezoelectric actuator datasheet. Available: https://www.mouser.com/datasheet

Register for free 6/phttpis

[5] PZT-5H material properties. Available: https://www.efunda.com/Materials/piezo/material _data/matdata_output.cfm?Material_ID=PZT-5H 